\title{
Hybrid krill herd optimizer for thermal power scheduling problem
}

\author{
Amarjeet Kaur ${ }^{1 *}$, Lakhwinder Singh ${ }^{2}$ and Jaspreet Singh Dhillon ${ }^{3}$ \\ Department of Electrical Engineering, Baba Banda Singh Bahadur Engineering College, Fatehgarh Sahib \& \\ Research Scholar, IKG-PTU, Jalandhar, Punjab, India ${ }^{1}$ \\ Department of Electrical Engineering, Baba Banda Singh Bahadur Engineering College, Fatehgarh Sahib, Punjab, \\ India $^{2}$ \\ Department of Electrical \& Instrumentation Engineering, Sant Longowal Institute of Engineering and Technology \\ Longowal, Punjab, India ${ }^{3}$ \\ Received: 16-August-2021; Revised: 19-December-2021; Accepted: 20-December-2021 \\ (C)2021 Amarjeet Kaur et al. This is an open access article distributed under the Creative Commons Attribution (CC BY) License, \\ which permits unrestricted use, distribution, and reproduction in any medium, provided the original work is properly cited.
}

\begin{abstract}
A hybridized meta-heuristic technique is applied to solve Economic-Environmental Power Dispatch (EEPD) problem. Krill Herd Algorithm (KHA) is a meta-heuristic technique of swarm intelligence based on populations of krill individuals and its motion for searching food. To improve the convergence characteristics of KHA, it is combined with a confined selective operator, termed as the Hybrid Krill Herd Optimizer (HKHO). In this technique, the krill's position is upgraded with confined krill individuals instead of the arbitrarily chosen individuals as processed in basic KHA. This proposed HKHO technique prevents entrapping of best possible solution in confined optima which means, it avoids the premature convergence of optimal solutions. A non-interactive multi-objective optimization technique is applied whereby the price penalty factor is applied to get scalar objective optimization in case of EEPD problem. The HKHO is implemented in small and medium standard test systems to show the applicability to solve EEPD problem. The developed optimizer is applied to validate the results on two power systems consisted of 6-and 40- thermal units. It gives $2.27 \%$ savings in fuel cost and $13.3 \%$ reduction in emission of pollutants for 6-thermal units' power systems with respects to the results undertaken for comparison. Whereas, 40-units' power system, depicts the conflicting nature of the objectives, when the fuel cost is decreased by $0.16 \%$ and emission of pollutants decreases by $0.04 \%$. In both the cases, the achieved results are comparable to already published work in terms of fuel cost and emission of pollutants as shown in tables of comparative analysis of achieved results. The examination of the results shows the satisfactory improvement in best possible solution.
\end{abstract}

\section{Keywords}

Confined selective operator, Economic dispatch, Emission dispatch, Hybrid krill herd optimizer, Price penalty factor.

\section{Introduction}

The active world is changing each and every day with the advancement of technology and its growing use in daily life, which in turns increases the use of electricity. To fulfil this increase in electricity demand, the electric power system is becoming more complex. The effective functioning of electric power system includes the satisfaction of its consumers with continuous and qualitative service of power supply. In today's world, the most important task is to use the available resources for thermal power generation at lowest price with intermittent power supply [1].

*Author for correspondence

1568
In the problem of Economic Load Dispatch (ELD), the output of dedicated thermal unit is allocated for minimum fuel cost while satisfying the generation constraints of the electric power system network. Also, the operational planning is required to run the power systems economically, with minimum pollution, maintaining security and reliability of the power system.

A number of investigations have been described in the literature to solve Economic-Environmental Power Dispatch (EEPD) problem. Initially, direct approaches, conventional methods and then linear programming, evolutionary programming, bio or nature inspired methods have been reported in the literature and are applied till date [2]. 
The study of economic-environmental dispatch draws the attention of researchers for reducing the pollutants to protect the environment. According to the international energy agency in $2011,45 \%$ of energy related carbon dioxide emission was coal based and it reaches to 31.6 Giga tons due to the combustion of coal. In the same year, China contributed the highest increase in emission by 720 million tons [3]. In view of the increasing concern with the environmental considerations, operating at minimum cost is not merely an indicator for scheduling of electric power. Now days, due to increase in environmental concern, there is a need of modification in the existing optimization methods and exploration of new methods according to environmental protection act [4]. Both economic and emission dispatch is equally significant issues in the power industry as the emission of pollutants can harm the health of all the living beings. These pollutants are $\mathrm{NO}_{\mathrm{x}}, \mathrm{SO}_{\mathrm{x}}$ and $\mathrm{CO}_{\mathrm{x}}$, which are being released into the atmosphere due to combustion of fuel used in thermal power plants. The conflicting and non-commeasurable nature of fuel cost and pollutant's emission are considered as the objectives of EEPD. The objectives are to optimize the power generated by thermal power generating units through minimizing the fuel cost and pollutant emission, simultaneously [5]. Therefore, to fulfil the future power demand of different consumers, more specific research is needed for best technical, economic and environmental conditions. The utilities would like to supply power to its customers with minimum environmental emission as well as fuel cost simultaneously [6].

The objectives of this paper are as follows:

1. To provide the study of literature review and analysis of the work related to economicenvironmental power dispatch problem.

2. To propose the methodology and its systematic implementation with the help of flow chart.

3 . To analyze the results obtained by the proposed optimizer and comparison of results with other optimization methods.

The motivation of this paper is as follows

- To consider the economic as well as environmental aspects for power generation scheduling.

- To explore the new technique and its modification along with its impact on the performance and applicability.

The contribution of this paper is as follows:
- To analyze the proposed optimizer in terms of its performance characteristics.

- Parametric analysis of approach with its results and limitations.

This paper consists of six sections. Section 1 presents the introduction. In section 2 literature review is discussed. In section 3, methodology is presented. In section 4, results are discussed. Discussion and analysis are covered in section 5. Finally, conclusions and future scope are presented in section 6.

\section{Literature review}

The operation of power generators should run at minimum operating fuel cost and environmental effect due to pollutants while fulfilling the generator constraints and power demand. The economicenvironmental power scheduling problems have been solved using gravitational search algorithm [7]. Environmental and economic power scheduling problem has been solved using an improved multiobjective interactive honey bee mating optimization while satisfying the operational constraints [8]. The multi-objective optimization problem has been solved by flower pollination, chaotic improved harmony search and whale optimization algorithms [9-11]. Also, sensitivity measure has been incorporated as a dispersion index, which needs to be minimized and best weight pattern approach has been implemented while solving a multi-objective thermal power scheduling problem $[12,13]$. The multi-objective electric scheduling problem has been solved using an emended salp swarm algorithm with the exterior penalty to handle the physical and operating constraints [14].

The combination of manta ray foraging optimization and gradient-based optimizer has been applied to multi-objective optimization problem [15]. Various economic emission dispatch problems have been solved with hybrid technique of teaching learning and Particle Swarm Optimization (PSO) [16]. An opposition-based harmony search has been implemented to deal with non-linear environmental and economic dispatch problem [17]. A hybrid optimization approach hybridizes differential evolution and harmony search algorithms to solve multi-objective scheduling problems with nonsmooth curves [18].

A combination of PSO and the simplex search method has been implemented to solve economicemission dispatch problems. PSO finds a global search in the exploration area, whereas simplex 
search method searches in the confined search area [19]. A technique based on piecewise-linear programming has been developed to solve economic dispatch problem with non-convex characteristics [20]. The overall cost of flexible sources has been minimized using a combination of distributed, robust optimization technique and self-adaptive line search method [21]. Bacterial foraging optimization has been proposed to solve economic-emission dispatch, which is based on natural choice of most favorable bacterium having a foraging strategy in the fitness function [22].

The ELD problem has been solved using conglomerated ion-motion and crisscross search optimizer [23]. A hybrid technique with firefly algorithm and self-regulated PSO has been implemented to solve the heat and ELD problem with transmission losses, valve point loading effect and Prohibited Operating Zones (POZ) [24]. An algorithm which is hybridized form of modified genetic algorithm and improved PSO has been implemented to environmental-economic dispatch problem [25].

Kho-Kho optimization technique has been proposed which is inspired by the strategies used by the players in the game. The algorithm has been applied to benchmark functions and active time combined heat and economic emission dispatch problem [26]. Quantum PSO based on differential evolution has been used to solve environmental, economic dispatch problem [27]. A new $\alpha$-constrained simplex method has been implemented on a multi-objective hydrothermal considering wind and solar power scheduling [28]. A hybridized technique of PSO and the simplex search method has been used to solve economic power dispatch of thermal generating units considering valve point loading, ramp-rate and POZ [29]. A hybrid evolutionary algorithm which is a combination of shuffle frog technique and PSO has been implemented to economic emission power dispatch problem considering physical and operational constraints [30]. A multi-objective hybrid bat method based on the combination of modified crowding distance sorting and non-dominated sorting method has been used to solve the combined economic and emission dispatch problem with different restrictions [31]. A combination of genetic algorithm and whale optimization algorithm has been implemented to economic-emission power dispatch to eliminate the conflict between economic and emission constraints and to revise the trade-off relationship among operating cost and emissions
[32]. A new multi-factorial immune algorithm along with an information transfer technique has been implemented to solve multiple objective optimization problems [33].

Multi-objective grey prediction evolution algorithm has adopted two learning processes to update the uniformity and diversity of the optimal solutions of economic and environmental dispatch [34]. The proposed algorithm is a combination of squirrel search algorithm and Pareto dominance theory, which has been applied to minimize total fuel cost and emission of pollutants [5]. An algorithm inspired by kernel tricks has been proposed and implemented to solve the multi-objective optimization problem along with weighed sum and Newton method [35]. The chaotic artificial ecosystem based algorithm was used to find the optimal solution which ensures the minimum fuel cost and pollutant's emission in the atmosphere [36]. A meta-heuristic algorithm, which is a combination of Newton method, gradient search rule and a local operator, has been applied to solve combined economic-emission dispatch problem [37]. A recurrent neural network has been proposed to minimize fuel cost and emission of pollutants with the effect of valve point loading effects and wind turbines [38]. A polar bear optimization and variants of the chaotic population have been proposed to solve combined economy and emission dispatch problem [39].

The purpose of an optimization procedure while solving a specific set of optimization problems may not ensure optimal solutions in another set of optimization problems. The optimization techniques can be integrated to exchange the good qualities of each other. All the above-mentioned optimization techniques are implemented on different ELD and EEPD problems and have the potential to find global solutions while considering the operating constraints. As mentioned in no lunch theorem [40], not any single optimization technique, individually or in the hybrid form is applicable to each and every optimization problem for obtaining the best global optimal solution with the same efficiency and characteristics. So, it is an essential requirement to explore new techniques and implement them for finding the global solutions for various EEPD problems. Mostly, the optimization lacks a balance between the exploration and exploitation, fast convergence, trapping into local solution and robustness of the global solution. It is worth to investigate for a better meta-heuristic search technique that has good balance between exploitation 
and exploration to enhance the convergence towards global solution, robustness of global solution, minimum number of parameters required for finetuning and have the capability to avoid the trapping into local solution. So, a scope of improvement always exists in the optimization procedures to get optimal solutions.

The objective of this paper is to apply the proposed optimizer to solve economic-environmental power dispatch problem. The Hybrid Krill Herd Optimizer (HKHO) is a combination of basic Krill Herd Algorithm (KHA) and confined selective operator. This hybrid technique enhances the robustness of optimal solution and convergence characteristics. The non-interactive approach is implemented whereby the price penalty factor is applied to unify the economic and environmental objectives of power dispatch problem into the scalar objective of dispatch problem. The HKHO is implemented on six and forty thermal power generating units' power system network neglecting transmission losses. Cost coefficients, active power constraints, emission of the pollutant's coefficients for each unit are undertaken. The thermal power generation schedule is also achieved. The results obtained by proposed optimizer are compared with the results obtained by already published techniques in terms of fuel cost and gaseous pollutant's emission to prove the competency of proposed optimizer.

\section{Methodology}

3.1Economic-environmental power dispatch (EEPD) problem

The economic-environmental power dispatch problem is structured mathematically in order to minimize conflicting objectives, i.e. operating fuel cost and pollutant's emission functions simultaneously, while satisfying the system constraints. The operating fuel cost has to consider valve point loading effect due to the presence of multiple valves in thermal generating unit which causes a variation in the quadratic operating fuel cost function. The sine wave ripples are augmented in quadratic fuel cost function. The EEPD problem is formulated as under:

Minimization of operating fuel cost is shown in Equation 1.

$$
\begin{aligned}
F\left(P_{i}\right)=\sum_{i=1}^{N G}\left[\alpha_{1 i} P_{i}^{2}\right. & +\beta_{1 i} P_{i}+\gamma_{1 i} \\
& \left.+\delta_{1 i}\left|\sin \left(\lambda_{1 i}\left(P_{i}^{\min }-P_{i}\right)\right)\right|\right]
\end{aligned}
$$

Minimize pollutant's emission as shown in Equation 2.

$E\left(P_{i}\right)=$

$\sum_{i=1}^{N G}\left[\alpha_{2 i} P_{i}^{2}+\beta_{2 i} P_{i}+\gamma_{2 i}+\delta_{2 i} e^{\lambda_{2 i} P_{i}}\right](k g / h)$

Subject to the equality constraint or energy balance equation is given as Equation 3.

$\sum_{i=1}^{N G} P_{i}=P_{D}+B_{O O}+\sum_{i=1}^{N G} B_{O i} P_{i}+\sum_{i=1}^{N G} P_{i}\left(\sum_{j=1}^{N G} B_{i j} P_{j}\right)$

The inequality constraint of active power is represented as Equation 4.

$P_{i}^{\min } \leq P_{i} \leq P_{i}^{\max } \quad(i=1,2, \ldots, N G)$

where $F(P)(\$ / h)$ is total operating cost function, NG is number of thermal powers generating units. $P_{i}$ is real thermal power output. The fuel cost coefficients are symbolized by $\alpha_{1 \mathrm{i}}\left(\$ / \mathrm{MW}^{2} \mathrm{~h}\right), \beta_{1 \mathrm{i}}(\$ / M W h), \gamma_{1 \mathrm{i}}(\$ / \mathrm{h}), \delta_{1 \mathrm{i}}(\$ / \mathrm{h})$ and $\lambda_{1 \mathrm{i}}(\mathrm{rad} / \mathrm{MW})$ are stated for $i^{\text {th }}$ thermal power generating unit. The emission coefficients are symbolized by $\quad \alpha_{2 \mathrm{i}}\left(\mathrm{kg} / \mathrm{MW}^{2} \mathrm{~h}\right)$, $\beta_{2 \mathrm{i}}(\mathrm{kg} / \mathrm{MWh}), \gamma_{2 \mathrm{i}}(\mathrm{kg} / \mathrm{h}), \quad \delta_{2 \mathrm{i}}(\mathrm{kg} / \mathrm{h})$, and $\lambda_{2 \mathrm{i}}\left(\mathrm{MW}^{-1}\right)$ are stated for $i^{\text {th }}$ thermal power generating unit. $P_{i}^{\min }(\mathrm{MW})$ and $P_{i}^{\max }(\mathrm{MW})$ are the lower and upper limits of active power generation of $i^{\text {th }}$ unit, respectively. $P_{D}$ (MW) is power demand. $B_{00}(\mathrm{MW}), B_{i 0}$ and $B_{i j}\left(M W^{-1}\right)$ are the loss coefficients obtained from load flow analysis [6].

The EEPD problem is to achieve global best power generation schedule with defined power balance equation and real power limits such that the total power generation cost as well as emission can be minimized. In this optimization problem, both operating cost function and pollutant's emission are transformed into singular objective using price penalty factor, where price penalty factor can be calculated by taking ratio among minimum or maximum of total operating cost and minimum or maximum emissions of specific generators [19]. EEPD problem is shown in Equation 5.

$F_{T}=F\left(P_{i}\right)+h E\left(P_{i}\right)$

Subject to the system constraints which are given by Equation 3 and Equation 4. Where $\mathrm{h}(\$ / \mathrm{kg})$ is the price penalty factor. 
The price penalty factor is stated as the ratio of operating fuel cost to emission of pollutants evaluated at either minimum or maximum generations [19]. The price penalty factor, $H F 1$ is defined as the ratio of operating fuel cost to emission of pollutants whereas both objectives are evaluated at minimum generation limit. The price penalty factor, $H F 2$ is defined as the ratio of operating fuel cost to emission of pollutants while both are evaluated at maximum generation limits. The average of two penalty factors is selected and is given as Equation 6 .

$h=\frac{H F_{1}+H F_{2}}{2}$

Where price penalty function, $H F_{1}=F\left(P^{\text {min }}\right) /$ $E\left(P^{\min }\right)$, Price penalty function, $H F_{2}=$ $F\left(P^{\max }\right) / E\left(P^{\max }\right) \quad$ with $P^{\min }=\left[\begin{array}{llll}P_{1}^{\min } & P_{2}^{\min } & \cdots & P_{N G}^{\min }\end{array}\right]^{T}$ and $P^{\max }=$ $\left[\begin{array}{llll}P_{1}^{\max } & P_{2}^{\max } & \cdots & P_{N G}^{\max }\end{array}\right]^{T}$

This penalty is being used in Equation 5 for decision making while calculating the fitness of the functions.

\subsection{Hybrid krill herd optimizer (HKHO)}

KHA is a swarm intelligence technique based on population of krill individuals and their herding behavior. Each krill moves in a particular direction to look ahead for food. The motion of krill herd is in multi-dimensional search space for searching food and the position of each krill is updated by three movements. First movement of krill is due to presence and displacement of other krill. Second movement is foraging which is associated with search for food. This shift in krill individual's position is acquired due to current food location and the prior spot of food. The third movement causes shift in position due to random flow of krill individual with respect to time. The combination of all the three displacement forms a vector which shows the activities of krill individual in searching area to find the food.

To improve the convergence characteristics of KHA, it is hybridized with a new confined selective operator, which is termed as hybrid krill herd optimizer. In addition to this, a constraint handling technique has been implemented so that the achieved optimal solutions should be feasible solution of power generation. The exclusive advantage of HKHO is the requirement of minimum number of parameters for fine tuning; therefore, it is effortless to implement the optimizer to solve optimization problems to discover the most favourable solutions with better convergence characteristics. Also, this optimizer uses stochastic random search rather than gradient search and parallel computation to find the optimal solutions with the non-requirement of any derivative information.

In next paragraphs, these three processes are shown mathematically and up gradation of the time dependent positions of krill individual are also explained [41]. The mathematical modeling to solve economic environmental power dispatch problem using $\mathrm{HKHO}$ is given as:

Initialization of krill individuals: Randomly, initialize active power of all thermal power generating units which should remain within their active power generation limits (Equation 7).

$$
\begin{array}{r}
P_{k i}=P_{i}^{\text {min }}+R(0.1)\left(P_{i}^{\text {max }}-P_{i}^{\text {min }}\right)(i \\
=1,2, \ldots, N G ; k=1,2, \ldots, N K)
\end{array}
$$

where real power vector is represented as, $P_{k i}=$ $\left[\begin{array}{llll}P_{k 1} & P_{k 2} & \cdots & P_{k N G}\end{array}\right]^{T}$. Equation (4) representing the power generation limits must be fulfilled. Start with another set of solutions, in case the assumed solution is not feasible. Apply constraint handling procedure to get the feasible solution.

Fitness evaluation: Equation 5 calculates the fitness of each krill of present set of individuals, giving feasible solution.

Induction Motion: To realize the presence of other krill around affects the motion of krill individual. The induced shift of $\mathrm{k}^{\text {th }}$ krill due to other krill is expressed as in Equation 8.

$N_{k}^{m}=\propto_{k} N_{k}^{\max }+\omega_{n} N_{k}^{m-1} \quad(k=1,2, \ldots, N K)$

Where

$$
\begin{aligned}
\propto_{k}=\sum_{j=1}^{N s} \frac{\left[F_{k}-F_{j}\right]}{\left[F_{k}^{w}-F_{i}^{b}\right]} \times \frac{\left[P_{k}-P_{j}\right]}{\left[\left|P_{k}-P_{j}\right|\right]+\varepsilon} \\
+2\left[R[0,1]+\frac{m}{I T_{\max }}\right] F_{k}^{\text {best }} P_{k}^{\text {best }}
\end{aligned}
$$

For $\mathrm{k}^{\text {th }} \mathrm{krill}$, the maximum induced motion is given by $N_{k}^{\max } . N_{k}^{m}$ and $N_{k}^{m-1}$ are the respective induced motions at the $\mathrm{m}^{\text {th }}$ and $(\mathrm{m}-1)^{\text {th }}$ movement. $F_{k}^{\text {best }}$ is the best value of fitness function and $P_{k}^{\text {best }}$ is the corresponding position of the $\mathrm{k}^{\text {th }}$ krill. IT $\max$ represents maximum iterations, Inertia weight is given by $\omega_{n} . F_{k}^{w}$ is worst position of krill individual. $F_{k}^{b}$ is the best position of krill. $F_{k}$ and $F_{j}$ are the fitness values of $\mathrm{k}^{\text {th }}$ and $\mathrm{j}^{\text {th }}$ individual, respectively. 
Ns is the number of neighboring krill. Current iteration is $m$.

Foraging Motion: In foraging motion factors are allied with the existing and last site of food. This situation is formulated as in Equation 9.

$$
F G_{k}^{m}=V_{f}\left[\begin{array}{c}
2\left(1-\frac{m}{I T_{\max }}\right) F_{k} \frac{\sum_{j=1}^{N s} \frac{P_{j}}{F_{j}}}{\sum_{j=1}^{N s} \frac{1}{F_{j}}}+F_{k}^{\text {best }} P_{k}^{\text {best }} \\
+\omega_{f} F G_{k}^{m-1}(k=1,2, \ldots, N K)
\end{array}\right]
$$

The $V_{f}$ is foraging rate to discover food, $\omega_{f}$ indicates weight of inertia. $F G_{k}^{m}$ and $F G_{k}^{m-1}$ are foraging motions of the $\mathrm{k}^{\text {th }}$ krill at the $\mathrm{m}^{\text {th }}$ and $(\mathrm{m}-1)^{\mathrm{th}}$ movements, respectively. This foraging motion is calculated on the basis of individual's motion and previous food location.

Random diffusion: This motion serves to improve the variety in krill members. The random diffusion process is given in Equation 10.

$D_{k}=\mu D_{\max }(k=1,2, \ldots, N K)$

Where $\mu \in[-1,1]$ is normalized directional vector. The maximum speed of diffusion is $D_{\max }$. Equations $(8,9$, and 10$)$ find out the induced motion, foraging motion and random diffusion. Equation 11 upgrades the location of individual krill.

$P_{k}^{m+1}=P_{k}^{m}+\left(N_{k}^{m}+F G_{k}^{m}+D_{k}\right) C_{t} \sum_{i=1}^{N G}\left(P_{i}^{\max }-\right.$

$\left.P_{i}^{\min }\right) \quad(k=1,2, \ldots, N K)$

Where $P_{k}^{m+1}$ is updated position of $\mathrm{k}^{\text {th }}$ krill and $P_{k}^{m}$ is old krill position. The position constant factor is $C_{t}$.

Mutation and Crossover: Equations 12, 13 and 14 adjust the location of each krill employing the mutation and crossover operators.

$P_{k i}=\left\{\begin{array}{l}P_{k i} \text { if rand } \leq C_{R} \\ P_{j i} \text { if rand } \geq C_{R}\end{array}(i=1,2, \ldots, N G ; k=\right.$

$1,2, \ldots, N K ; k \neq j$, )

Where crossover probability is $C_{R} \cdot j$ is random integer $\in[1, N K]$.

The position of every krill is upgraded by mutant operator. The rate of mutation is $M_{R}$. Two vectors $P_{m i}$ and $P_{n i}$ are selected randomly. Optimal solution is $P_{b e s t, i}$ and the mutant solution is $P_{k i}^{\text {mutant }}$. $P_{k i}^{\text {mutant }}=P_{\text {best }, i}+F_{R}\left(P_{m i}-P_{n i}\right)(i=$ $1,2, \ldots, N G ; k=1,2, \ldots, N K ; m \neq n \neq k)$
$P_{k i}^{m o d}$ is the modified value of krill's position that depends on mutation rate and is chosen from $P_{k i}^{\text {mutant }}$ and $P_{k i}[41]$.

$P_{k i}^{\text {mod }}=\left\{\begin{array}{ll}P_{k i}^{\text {mutant }} & ; \text { rand } \leq M_{R} \\ P_{k i} & ; \text { rand }>M_{R}\end{array}(k=\right.$

$1,2, \ldots, N K, i=1,2, \ldots, N G)$

Equation 15 upgrades the position of krill individual employing a preferred krill to enhance the quality of global solution. The position of krill individual is updated with a selected individual position $P_{i}^{\text {selected }}$ to find the new updated position $P_{i}^{\text {new }}$ [42].

$P_{i}^{\text {new }}=P_{i}^{\text {selected }}+\operatorname{Rand}(-1,1)\left(P_{i}^{\text {selected }}-\right.$

$\left.P_{i}^{\text {old }}\right) \quad(i=1,2, \ldots, N G)$

And, old position of the respective krill individual is denoted by $P_{i}^{\text {old }}$.

Stopping criterion: When, the iteration counter, $\mathrm{m}$ reaches to its maximum, $I T_{\max }$ set value, the program stops.

\subsection{Constraints handling strategy}

The procedure of handling the system constraints in economic-environmental power dispatch problem is given below. To find the feasible solution, the difference in power requirement and actual power generation in the system can be given as shown in Equation 16.

$\Delta P_{D}=$

$P_{D}+B_{O O}+\sum_{i=1}^{N G} B_{O i} P_{i}+\sum_{i=1}^{N G} P_{i}\left(\sum_{j=1}^{N G} B_{i j} P_{j}\right)-$

$\sum_{i=1}^{N G} P_{i}$

If the condition $\left|\Delta P_{D}\right|=0$, the constraint is satisfied, that means, the total generation of power by all the thermal generating units meets the power demand. So, there is no need to mend the solution. If the condition $\left|\Delta P_{D}\right| \neq 0$ and the constraint is not satisfied, then there is need to mend the generation so that power balance constraint given by Equation 16 is fulfilled. When $\Delta P_{D}>0$, there is a need to raise the power generation and when $\Delta P_{D}<0$, there is a need to cut the power generation. This management of constraint is framed as.

$P_{i}=$

$\left\{\begin{array}{c}P_{i}+\min \left(\left(P_{i}^{\max }-P_{i}\right) z_{i},\left(\frac{\left|\Delta P_{D}\right|}{\sum_{i=1}^{N G} P_{i}}\right) P_{i}\right):\left(\Delta P_{D}>0\right) \\ P_{i}-\min \left(\left(P_{i}-P_{i}^{\min }\right) z_{i},\left(\frac{\left|\Delta P_{D}\right|}{\sum_{i=1}^{N D} P_{i}}\right) P_{i}\right):\left(\Delta P_{D}<0\right)\end{array}(i=\right.$

$1,2, \ldots, N G)$ 
Where, $\mathrm{P}_{\mathrm{i}}$ is power generation, $P_{i}^{\min }, P_{i}^{\max }$ are minimum and maximum limits of power generation, $\Delta P_{D}$ is given by Equation (16), $z_{i}$ is random number within range $[0,1]$. This systemized mathematical formulation yields power generation proportional to power requirement by consumers. The stopping criteria is to set a very small constant value and the cycle is repeated until $\Delta P_{D}$ becomes smaller than small constant value.
Inequality constraint given by Equation (4) is adjusted by replacement method. It means the generation is set the corresponding limits on violation of the limit.

\subsection{Flow chart of hybrid krill herd optimizer (HKHO)}

Figure 1 shows the flow chart of KHA with constraint handling strategy

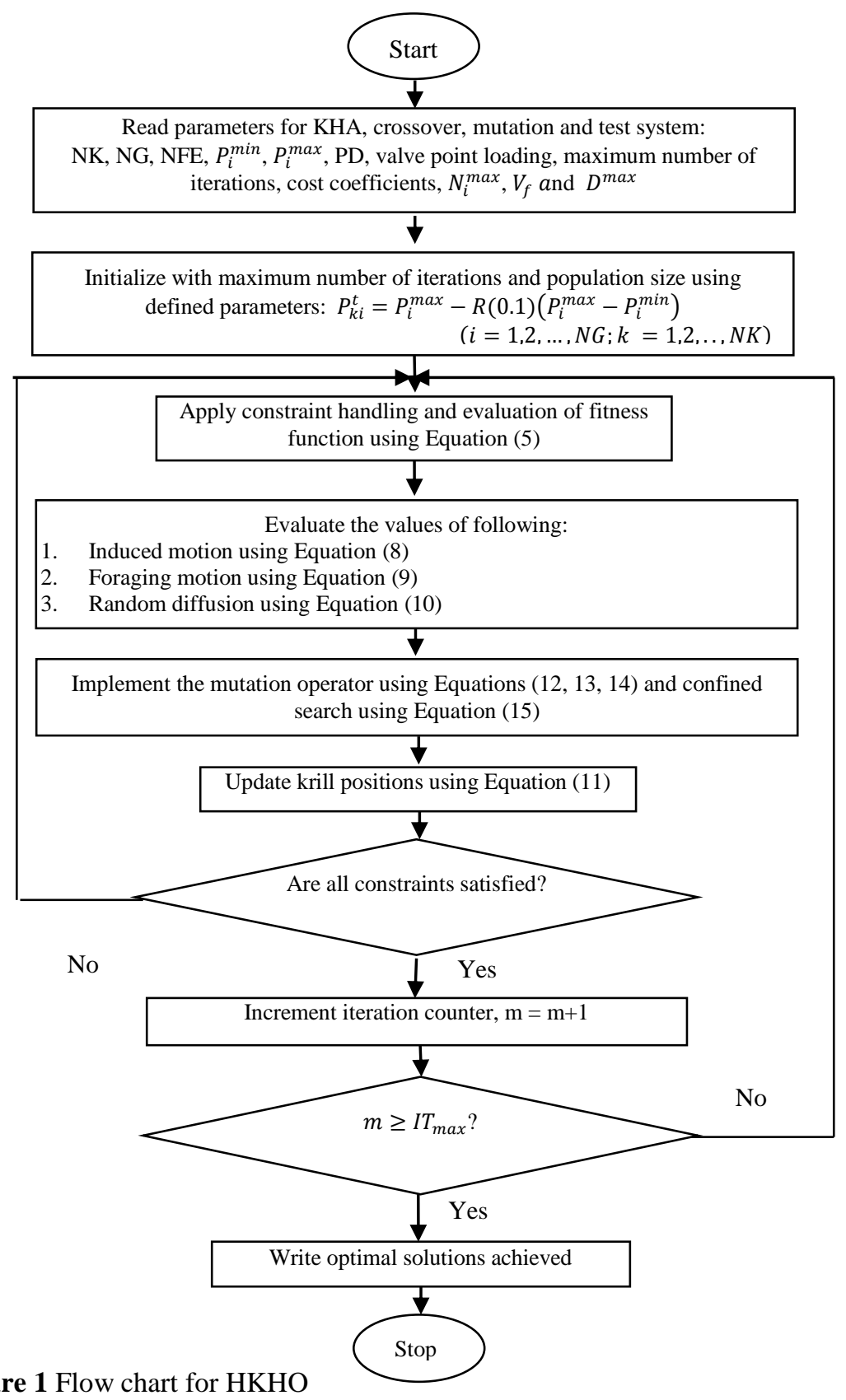




\subsection{Parameters selection}

The developed program is executed for 25 independent runs and each run is executed for 200 iterations. The parameters for KHA are given as, $N_{i}^{\max }$ is 0.01 in induced motion. In foraging motion the value of $V_{f}$ is 0.02 and maximum diffused speed is $D_{\max } \epsilon[0.02,0.005]$. Number of krill is taken as 100. The position constant factor, $C_{t} \in[0,2]$ is calculated for the up-gradation of position of krill individual, using the following formula (Equation 18).

$$
\begin{aligned}
& C_{t}=C_{\text {tmax }}- \\
& \left(C_{\text {tmax }}-C_{\text {tmin }}\right) \times \\
& \frac{m \text { (Current iteration) }}{}
\end{aligned}
$$

$\overline{I T_{\max } \text { (Maximum number of iterations) }}$

The inertia weights in case of induced motion $\omega_{n}$ and foraging motion $\omega_{f}$ are calculated using chaotic sequences. These chaotic sequences are very sensitive to initial conditions and parameters. These sequences are combined with heuristic algorithm to avoid the trapping into confined optimum solution. The expression for logistic map is: $X^{t+1}=4 X^{t}\left(1-X^{t}\right) ; X \notin[0,0.25,0.5,0.75,1]$
The value of chaotic variable is distributed between $(0,1)$ and initially $X^{0}$ is set to 0.2027 .

While applying the differential operators, a mutant vector is generated using best, worst and mean population vector with random numbers generated by chaotic variables and crossover probability $C_{R}$ is taken as $C_{R}=0.01+0.15 R_{Y}$ where $R_{Y}$ is calculated as chaotic variable. Though applying confined selective operator, a constant value of mutation rate, $M_{R}$ is considered as 150 .

\section{Test systems and results}

To validate the feasibility of proposed HKHO, two standard test systems consisting of six and forty thermal generating units are undertaken [43].

\subsection{Test system 1}

This electric power test system consists of six thermal power generators. Table 1 shows the active power limits and cost coefficients and Table 2 shows the pollutant emission coefficients of each unit. The

\begin{tabular}{|c|c|c|c|c|c|}
\hline Unit & $\begin{array}{l}P_{i}^{\min } \\
(\mathrm{MW})\end{array}$ & $\begin{array}{l}P_{i}^{\max } \\
(\mathbf{M W})\end{array}$ & $\begin{array}{l}\alpha_{1 i} \\
\left(\$ / M W^{2} h\right)\end{array}$ & $\begin{array}{l}\beta_{1 i} \\
(\$ / M W h)\end{array}$ & $\begin{array}{l}\gamma_{1 i} \\
(\$ / h)\end{array}$ \\
\hline 1 & 10 & 125 & 756.800 & 38.5390 & 0.15247 \\
\hline 2 & 10 & 150 & 451.325 & 46.1591 & 0.10587 \\
\hline 3 & 35 & 210 & 1243.5311 & 38.3055 & 0.03546 \\
\hline 4 & 35 & 225 & 1049.9977 & 40.3965 & 0.02803 \\
\hline 5 & 125 & 315 & 1356.6592 & 38.2704 & 0.01799 \\
\hline 6 & 130 & 325 & 1658.5696 & 36.3278 & 0.02111 \\
\hline
\end{tabular}
power demand $P_{D}$ is considered as $1200 \mathrm{MW}$.

Table 1 Active power limits and cost coefficients

Table 2 Emission coefficients of six thermal generating units

\begin{tabular}{llll}
\hline Unit & $\begin{array}{l}\boldsymbol{\alpha}_{\mathbf{2 i}} \\
\left(\mathrm{Kg} / M W^{2} h\right)\end{array}$ & $\begin{array}{l}\boldsymbol{\beta}_{\mathbf{2 i}} \\
(\mathrm{Kg} / M W h)\end{array}$ & $\begin{array}{l}\boldsymbol{\gamma}_{\mathbf{2 i}} \\
(\mathrm{Kg} / M W h)\end{array}$ \\
\hline 1 & 13.8593 & 0.32767 & 0.00419 \\
\hline 2 & 13.8593 & 0.32767 & 0.00419 \\
\hline 3 & 40.2669 & -0.54551 & 0.00683 \\
\hline 4 & 40.2669 & -0.54551 & 0.00683 \\
\hline 5 & 42.8955 & -0.51116 & 0.00461 \\
\hline
\end{tabular}

The program for proposed HKHO is executed for 25 runs and implemented to solve EEPD problem. The obtained schedule of active power generation, $P_{i}(i=1,2, \ldots, N G)$ is shown in Table 3. The operating fuel cost and pollutant's emission values are compared with the results obtained by other three methods viz. Multi-objective Differential Evolution (MODE), Teaching Learning Based Optimization (TLBO); Quasi-opposition Teaching Learning based optimization (QOTLBO) [43]. Table 3 depicts the comparison of results, which reveals that fuel cost is $63478(\$ / \mathrm{h})$ and emission of pollutants is $1133(\mathrm{~kg} / \mathrm{h})$ obtained by proposed HKHO, which is less than the value of fuel cost and emission of pollutant by MODE, QOTLBO and TLBO.

Table 4 shows the satisfaction of active power generation constraint, as the active power generation by all the six thermal power generating units lies in their respective power generation limits. First and 
second units are generating power equal to their maximum limits and the remaining four generators are generating power quite close to the maximum power generation limits. This constraint is taken care of, by the application of constraint handling technique as mentioned in section 5 .

The energy balance equation or equality constraint is satisfied by calculating the difference between power demand and actual power generation. The calculated difference is denoted by DPD and is equal to $0.988255 \mathrm{E}-04$ in the case of minimum value of combined economic and emission objective function. Table 5 depicts the comparison of achieved results in terms of minimum operating fuel cost and minimum pollutant's emission as compared to other methods.

Table 3 Comparison of operating fuel cost and pollutant emission

\begin{tabular}{lllll}
\hline \multirow{2}{*}{ Unit, $\mathbf{i}$} & \multicolumn{4}{c}{ Power generation, $\boldsymbol{P}_{\boldsymbol{i}}(\mathbf{M W})$ by applied methods } \\
\cline { 2 - 5 } & MODE [43] & QOTLBO [43] & TLBO [43] & Proposed HKHO \\
\hline 1 & 108.6284 & 107.3101 & 107.8651 & 125.000 \\
\hline 2 & 115.9456 & 121.4970 & 121.5676 & 150.000 \\
\hline 3 & 206.7969 & 206.5010 & 206.1771 & 186.002 \\
\hline 4 & 210.0000 & 206.5826 & 205.1879 & 186.649 \\
\hline 5 & 301.8884 & 304.9838 & 306.5555 & 276.016 \\
\hline 6 & 308.4127 & 304.6036 & 304.1423 & 276.333 \\
\hline Fuel cost $\mathbf{( \$ / h )}$ & 64843 & 64912 & 64922 & $\mathbf{6 3 4 7 8}$ \\
\hline Emission $\mathbf{( k g / h )}$ & 1286 & 1281 & 1281 & $\mathbf{1 1 3 3}$ \\
\hline
\end{tabular}

Table 4 Active power generation schedule and constraints for six thermal power generating units

\begin{tabular}{llll}
\hline Unit, $\mathbf{i}$ & $\boldsymbol{P}_{\boldsymbol{i}}^{\boldsymbol{m} \boldsymbol{i n}}(\mathbf{M W})$ & $\boldsymbol{P}_{\boldsymbol{i}}(\mathbf{M W})$ & $\boldsymbol{P}_{\boldsymbol{i}}^{\boldsymbol{m a x}}(\mathbf{M W})$ \\
\hline 1 & 10 & 125.000 & 125 \\
\hline 2 & 10 & 150.000 & 150 \\
\hline 3 & 35 & 186.002 & 210 \\
\hline 4 & 35 & 186.649 & 225 \\
\hline 5 & 125 & 276.016 & 315 \\
\hline 6 & 130 & 276.333 & 325 \\
\hline Total & & 1200.0 & \\
\hline
\end{tabular}

Table 5 Comparative analysis of achieved results

\begin{tabular}{lll}
\hline Method & Fuel cost $\mathbf{( \$ / h )}$ & Emission $(\mathbf{k g} / \mathbf{h})$ \\
\hline PDE [43] & 64920 & 1281 \\
\hline NSGA-II [43] & 64962 & 1285 \\
\hline SPEA-2 [43] & 64884 & 1285 \\
\hline Proposed HKHO & $\mathbf{6 3 4 7 8}$ & $\mathbf{1 1 3 3}$ \\
\hline
\end{tabular}

The fuel cost obtained by Pareto Differential Evolution (PDE) is $64920(\$ / \mathrm{h})$, Non-dominated Sorting Genetic Algorithm-II (NSGA-II) is 64962 $(\$ / \mathrm{h})$ and Strength Pareto Evolutionary Algorithm 2 (SPEA-2) is $64884(\$ / \mathrm{h})$ [43].

All the mentioned values of fuel cost are higher than the fuel cost obtained by proposed optimizer which is $63478(\$ / \mathrm{h})$. The emission obtained by PDE is 1281 $(\mathrm{kg} / \mathrm{h})$, NSGA-II is $1285(\mathrm{~kg} / \mathrm{h})$ and SPEA-2 is 1285 $(\mathrm{kg} / \mathrm{h})$, where emission obtained by proposed optimizer is $1133 \mathrm{~kg} / \mathrm{h}$ and is less than the values of other techniques as mentioned above. It gives $2.27 \%$ saving in fuel cost and $13.3 \%$ reduction of emission of pollutants.

To check the randomness of results obtained, t-test is performed. The probability values are less than their respective critical values as shown in Table 6.

Table 6 T-test performance for six thermal generating units

\begin{tabular}{lc}
\hline & T-test measures \\
\hline One-tail $\mathrm{P}(\mathrm{T}<=\mathrm{t})$ & $1.77402 \mathrm{E}-08$ \\
\hline One-tail $\mathrm{t}-\mathrm{Critical}$ & 1.710882067 \\
\hline Two-tails $\mathrm{P}(\mathrm{T}<=\mathrm{t})$ & $3.54804 \mathrm{E}-08$ \\
\hline Two-tails $\mathrm{t}-\mathrm{Critical}$ & 2.063898547 \\
\hline
\end{tabular}


The probability value is $1.77402 \mathrm{E}-08$ (one tail) is less than 1.710882067 (critical) and 3.54804E-08 (two tails) is less than 2.063898547 (critical).

The statistical measures give the mean and maximum values of fuel cost as $63478.0(\$ / \mathrm{h})$ and $63478.1(\$ / \mathrm{h})$ and the calculated standard deviation is $0.37031 \mathrm{E}-01$ and minimum Number of Function Evaluation (NFE) is 2594650.Figure 2 and Figure 3 represent the variation in operating fuel cost and emission of pollutant with respect to number of runs for test system 1 depicting robustness of the solution, respectively.

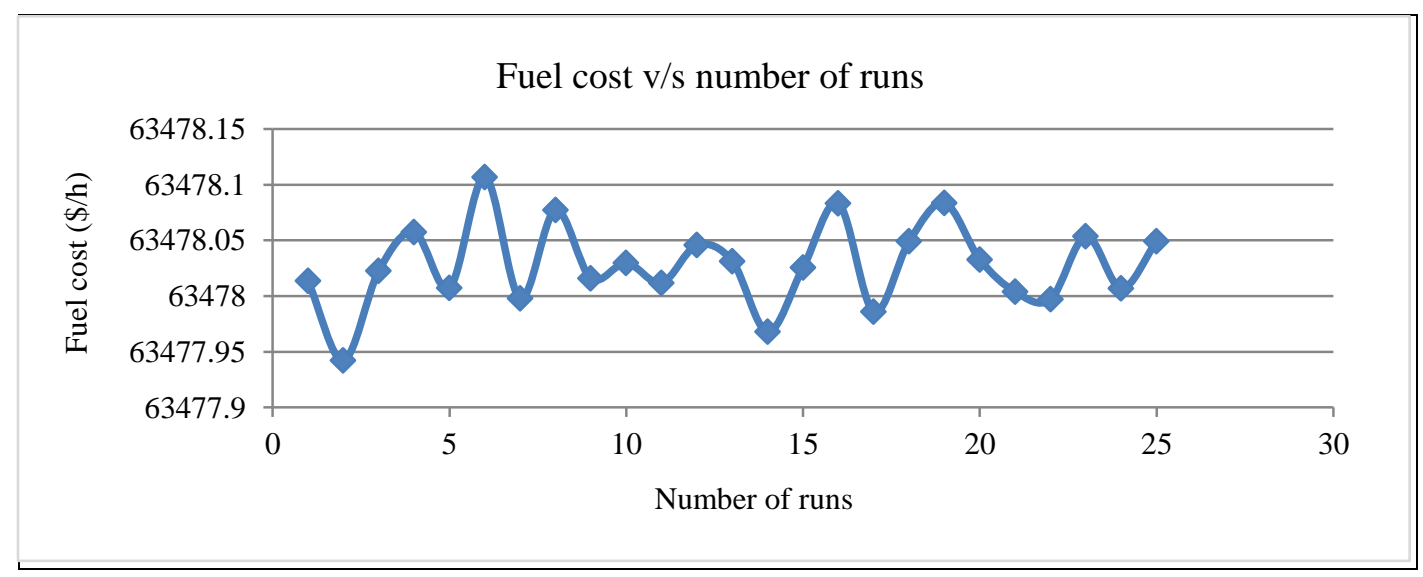

Figure 2 Fuel cost variation for test system 1

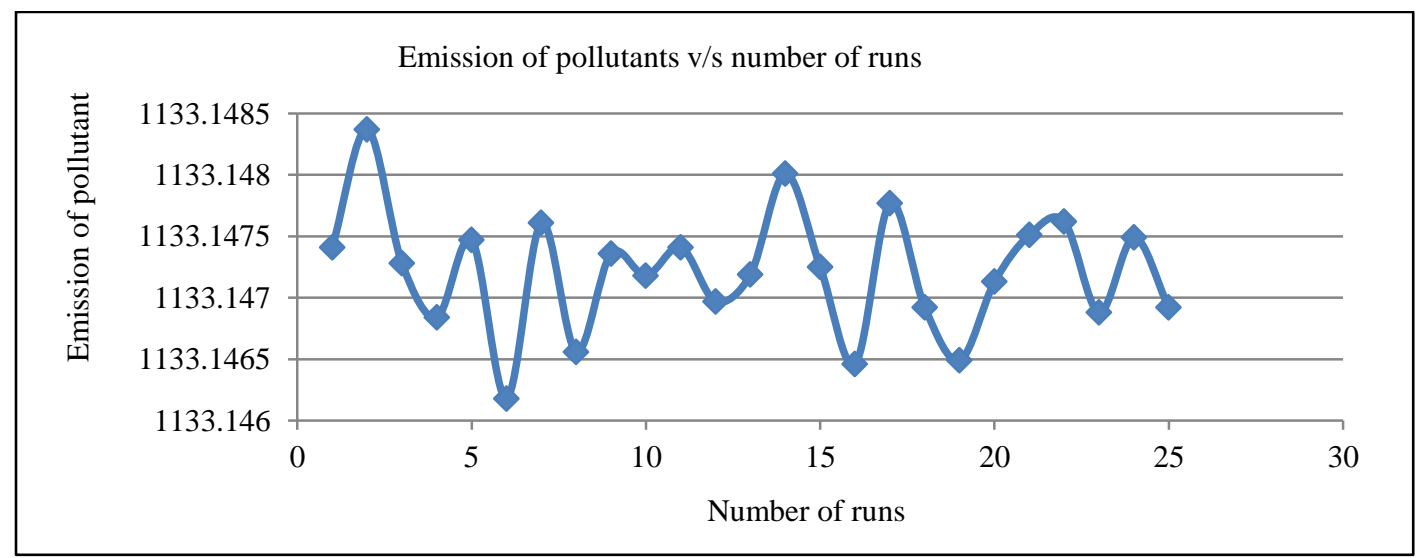

Figure 3 Emission variation for test system 1

\subsection{Test system 2}

A standard electric power test system of forty thermal power generating units having non-convex characteristics is considered to validate the proposed optimizer. The valve point loading effect is undertaken by adding valve point loading coefficients in the system. The data for cost coefficients and emission coefficients are taken from reference [7]. The power demand $P_{D}$ is taken as $10,500 \mathrm{MW}$ and the program is executed for 25 runs. The obtained schedule of active power generation, $P_{i}(\mathrm{i}=1$, $2, \ldots, \mathrm{NG})$ is depicted in Table 7 . The operating fuel cost and pollutant's emission is compared with three methods viz. TLBO, QOTLBO and DE [43]. Table 7 depicts the comparison of results, which reveals that the results achieved by proposed optimizer in terms 1577 of minimum operating fuel cost and minimum pollutant's emission are compared with other methods. The fuel cost obtained by TLBO is 129955 $(\$ / h)$, QOTLBO is $129952(\$ / h)$ and DE is 129961 $(\$ / h)[43]$. All the values of fuel cost mentioned in above methods are higher than the fuel cost obtained by proposed optimizer which is $129744(\$ / \mathrm{h})$. The emission obtained by TLBO is $176682.5(\mathrm{~kg} / \mathrm{h})$, QOTLBO is $176683.5(\mathrm{~kg} / \mathrm{h})$ and DE is 176683.5 $(\mathrm{kg} / \mathrm{h})$ [43] whereas emission obtained by proposed optimizer is $176753.2(\mathrm{~kg} / \mathrm{h})$, which is less than the emission obtained by above mentioned techniques. This system depicts the conflicting nature of the objectives. The operating cost is decreased by $0.16 \%$ and emission of pollutants decreases by $0.04 \%$.

Table 8 represents the satisfaction of active power 
Amarjeet Kaur et al.

generation constraints and total demand. Out of 40 units, eight units are generating power exactly equal to maximum active power generation of that particular unit. Whereas, the four units are close to their respective minimum active power generation limit. Most of the remaining twenty-eight units are generating power which is close to their respective maximum power generation limits.

Table 7 Comparison of fuel cost and pollutant's emission

\begin{tabular}{|c|c|c|c|c|}
\hline \multirow[t]{2}{*}{ Unit, i } & \multicolumn{4}{|c|}{ Power generation, $P_{i}(\mathrm{MW})$ by applied methods } \\
\hline & QOTLBO [43] & TLBO [43] & DE [43] & Proposed HKHO \\
\hline 1 & 113.9986 & 110.8684 & 114.000 & 114.000 \\
\hline 2 & 113.9992 & 114.0000 & 114.000 & 114.000 \\
\hline 3 & 119.9998 & 120.0000 & 120.000 & 120.000 \\
\hline 4 & 169.3712 & 169.2755 & 169.2933 & 171.3607 \\
\hline 5 & 97.0000 & 97.0000 & 97.000 & 97.000 \\
\hline 6 & 124.2561 & 124.2907 & 124.2828 & 125.1440 \\
\hline 7 & 299.7114 & 299.7180 & 299.4564 & 299.9987 \\
\hline 8 & 297.9140 & 297.9220 & 297.8554 & 298.2422 \\
\hline 9 & 297.2581 & 297.2571 & 297.1332 & 297.4635 \\
\hline 10 & 130.0000 & 130.2007 & 130.000 & 130.0016 \\
\hline 11 & 298.4145 & 298.3876 & 298.5980 & 300.2156 \\
\hline 12 & 298.0278 & 298.2678 & 297.7226 & 299.7909 \\
\hline 13 & 433.5600 & 433.5655 & 433.7471 & 433.5298 \\
\hline 14 & 421.7308 & 421.3705 & 421.9529 & 420.4447 \\
\hline 15 & 422.7783 & 422.5759 & 422.6280 & 421.4961 \\
\hline 16 & 422.7808 & 422.4581 & 422.9508 & 421.6273 \\
\hline 17 & 439.4144 & 439.5159 & 439.2581 & 441.2540 \\
\hline 18 & 439.4038 & 439.4102 & 439.4411 & 441.2413 \\
\hline 19 & 439.4128 & 439.2949 & 439.4908 & 439.0905 \\
\hline 20 & 439.4082 & 439.7375 & 439.6189 & 439.0933 \\
\hline 21 & 439.4460 & 439.5429 & 439.2250 & 439.0459 \\
\hline 22 & 439.4469 & 439.5357 & 439.6821 & 439.0639 \\
\hline 23 & 439.7680 & 439.2180 & 439.8757 & 439.4262 \\
\hline 24 & 439.7708 & 439.9235 & 439.8937 & 439.3920 \\
\hline 25 & 440.1155 & 440.3795 & 440.4401 & 439.7114 \\
\hline 26 & 440.1110 & 439.9939 & 439.8408 & 439.6782 \\
\hline 27 & 28.9934 & 28.9930 & 28.7758 & 26.5264 \\
\hline 28 & 28.9931 & 29.0119 & 29.0747 & 26.4921 \\
\hline 29 & 28.9943 & 29.0599 & 28.9047 & 26.5136 \\
\hline 30 & 97.0000 & 97.0000 & 97.000 & 97.0000 \\
\hline 31 & 172.3331 & 172.3063 & 172.4036 & 172.9287 \\
\hline 32 & 172.3324 & 172.3457 & 172.3956 & 172.9538 \\
\hline 33 & 172.3304 & 172.4643 & 172.3144 & 172.9204 \\
\hline 34 & 199.9996 & 200.000 & 200.000 & 200.000 \\
\hline 35 & 199.9989 & 200.000 & 200.000 & 200.000 \\
\hline 36 & 199.9998 & 200.000 & 200.000 & 200.000 \\
\hline 37 & 100.8369 & 100.9472 & 100.8765 & 101.4023 \\
\hline 38 & 100.8385 & 100.8250 & 100.000 & 101.4522 \\
\hline 39 & 100.8378 & 100.8901 & 100.7789 & 101.3943 \\
\hline 40 & 439.4138 & 439.3752 & 439.1894 & 439.1041 \\
\hline Fuel cost $(\$ / \mathbf{h})$ & 129955 & 129952 & 129961 & 129744 \\
\hline Emission (kg/h) & 176682.5 & 176683.5 & 176683.5 & 176753.2 \\
\hline$\sum P_{i}(\mathbf{M W})$ & 10500 & 10496.93 & 10499.1 & 10500 \\
\hline
\end{tabular}


Table 8 Active power generation schedule and constraints for forty thermal power generating units

\begin{tabular}{|c|c|c|c|}
\hline Unit, i & $P_{i}^{\min }(\mathrm{MW})$ & $P_{i}(\mathbf{M W})$ & $P_{i}^{\max }(\mathrm{MW})$ \\
\hline 1 & 36 & 114.000 & 114 \\
\hline 2 & 36 & 114.000 & 114 \\
\hline 3 & 60 & 120.000 & 120 \\
\hline 4 & 80 & 171.3607 & 190 \\
\hline 5 & 47 & 97.000 & 97 \\
\hline 6 & 68 & 125.1440 & 140 \\
\hline 7 & 110 & 299.9987 & 300 \\
\hline 8 & 135 & 298.2422 & 300 \\
\hline 9 & 135 & 297.4635 & 300 \\
\hline 10 & 130 & 130.0016 & 300 \\
\hline 11 & 94 & 300.2156 & 375 \\
\hline 12 & 94 & 299.7909 & 375 \\
\hline 13 & 125 & 433.5298 & 500 \\
\hline 14 & 125 & 420.4447 & 500 \\
\hline 15 & 125 & 421.4961 & 500 \\
\hline 16 & 125 & 421.6273 & 500 \\
\hline 17 & 220 & 441.2540 & 500 \\
\hline 18 & 220 & 441.2413 & 500 \\
\hline 19 & 242 & 439.0905 & 500 \\
\hline 20 & 242 & 439.0933 & 500 \\
\hline 21 & 254 & 439.0459 & 550 \\
\hline 22 & 254 & 439.0639 & 550 \\
\hline 23 & 254 & 439.4262 & 550 \\
\hline 24 & 254 & 439.3920 & 550 \\
\hline 25 & 254 & 439.7114 & 550 \\
\hline 26 & 254 & 439.6782 & 550 \\
\hline 27 & 10 & 26.5264 & 150 \\
\hline 28 & 10 & 26.4921 & 150 \\
\hline 29 & 10 & 26.5136 & 150 \\
\hline 30 & 47 & 97.0000 & 97 \\
\hline 31 & 60 & 172.9287 & 190 \\
\hline 32 & 60 & 172.9538 & 190 \\
\hline 33 & 60 & 172.9204 & 190 \\
\hline 34 & 90 & 200.000 & 200 \\
\hline 35 & 90 & 200.000 & 200 \\
\hline 36 & 90 & 200.000 & 200 \\
\hline 37 & 25 & 101.4023 & 110 \\
\hline 38 & 25 & 101.4522 & 110 \\
\hline 39 & 25 & 101.3943 & 110 \\
\hline 40 & 242 & 439.1041 & 550 \\
\hline Total & & 10500.00 & \\
\hline
\end{tabular}

The energy balance equation or equality constraint is satisfied by calculating difference between power demand and actual power generation. The calculated difference is denoted by DPD and is equal to $0.144716965 \mathrm{E}-03$ in the case of minimum value of EEPD objective function. To check the randomness of results obtained, t-test is performed. The probability values are less than their respective critical values as given in Table 9.
Table 9 T-test performance for forty thermal generating units

\begin{tabular}{lr}
\hline & T-test measures \\
\hline One-tail $\mathrm{P}(\mathrm{T}<=\mathrm{t})$ & $2.19967 \mathrm{E}-08$ \\
\hline One-tail $\mathrm{t}-\mathrm{Critical}$ & 1.713871517 \\
\hline Two-tails $\mathrm{P}(\mathrm{T}<=\mathrm{t})$ & $4.39934 \mathrm{E}-08$ \\
\hline Two-tails t-Critical & 2.068657599 \\
\hline
\end{tabular}

The probability value is $2.19967 \mathrm{E}-08$ (one tail) is less than 1.713871517 (critical) and 4.39934E-08 (two tails) is less than 2.068657599 (critical). 
The statistical measures give the mean and maximum values of fuel cost as $129746(\$ / \mathrm{h})$ and $129748(\$ / \mathrm{h})$. The calculated standard deviation is 1.394 and minimum number of function evaluation is 2521300 .
Figure 4 and Figure 5 represent the variation in operating fuel cost and emission of pollutant with respect to number of runs for test system 2 depicting robustness of the solution, respectively.

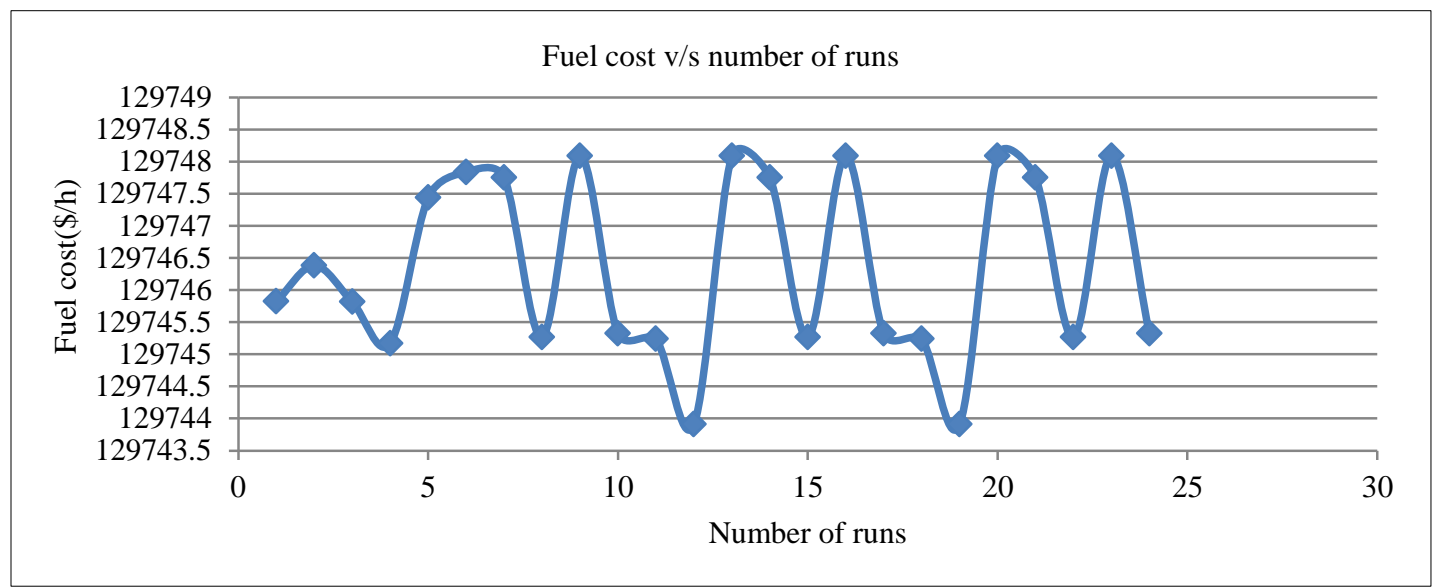

Figure 4 Fuel cost variation for test system 2

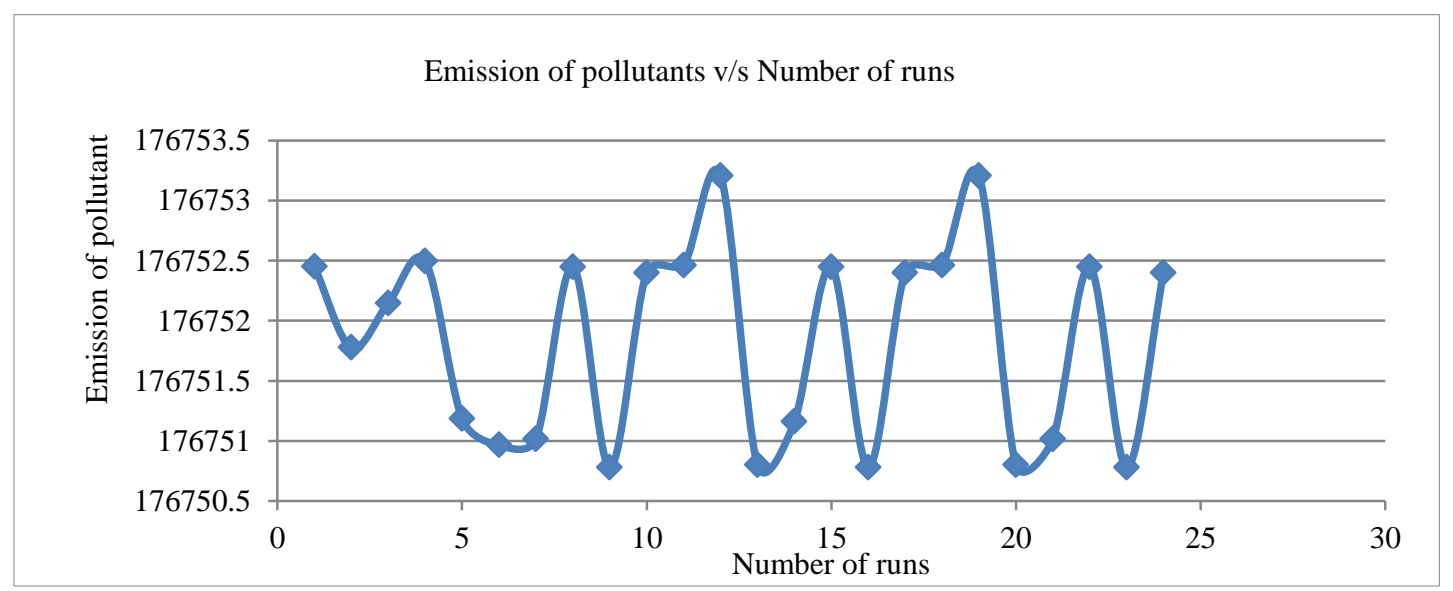

Figure 5 Emission variation for test system 2

\section{Discussions}

The outcome of the proposed HKHO is discussed in the ensuing sub-sections when implemented to solve economic environmental load dispatch problems.

\subsection{General discussion of results}

The proposed optimizer is implemented on two systems: one is small test system with six thermal power generating units while the second one is a medium power system with forty thermal power generating units. The results obtained with first test system depicts that defined equality and inequality constraints in subsection 3.1 are fulfilled. Inequality constraint is considered for each power generating unit and its fulfilment is depicted in Table 4. In case of each run, DPD is also calculated to confirm the fulfilment of equality constraints. In test system 2, valve point loading effect is also taken as one of the constraints. So, while executing the program, all the calculations are performed considering valve point loading effect as given in Equation (1). Along with this constraint, the fulfilment of inequality constraint is depicted in Table 8 and the value of DPD is also given along with other numerical values to prove the fulfilment of equality constraints.

The graphs showing the variation of operating fuel cost and pollutant emission with respect to the number of runs give an idea about the value of fuel cost and emission at one particular run. T-test is performed to check the randomness of the results obtained if all the results in 25 runs are considered as 
it helps to prove the validity of obtained results.

The fuel cost and pollutant emission are the objectives to be minimized, simultaneously. It is satisfied with the execution of programs on standard test system 1 which gives $2.27 \%$ savings in fuel cost and $13.3 \%$ reduction of emissions of pollutants and in test system 2, the operating cost is decreased by $0.16 \%$ and emission of pollutants decreased by $0.04 \%$. The proposed optimizer maintains a balance between exploration and exploitation which can avoid the trapping into local region and leads to better convergence properties. The constraint handling strategy is providing support to get the feasible solutions.

The t-test performance reveals the robustness of the global solution. The fine tuning of few parameters plays an important role for easy implementation.

Hence, through comparative analysis, it is clear that the proposed optimizer is more effective than the existing methods with respect to the performance characteristics. Complete list of abbreviations is shown in Appendix I.

\subsection{Limitations}

The increase in the number of constraints in economic, environmental power dispatch problem increases the complexity of the program. In more practical optimization problem, all the physical constraint viz, valve point loading effect, ramp rate limits, prohibited operating zones and minimization of transmission losses are being considered. Because of a number of parameters involved, there is possibility that with the consideration of all the physical constraints in the system, there could be a need to change the parameters depending upon the results, so it will further increase the complexity of the program.

\section{Conclusions and future scope}

In this research work, HKHO is developed which enhances the convergence properties of basic KHA by hybridizing with a new confined selective operator. The HKHO solves economic-environmental thermal power load dispatch problem ignoring transmission losses. The comparative analysis of achieved results with recently published techniques is presented. The statistical measures in terms of minimum, maximum values of fuel cost and standard deviation are calculated to show the strength of the optimizer. T-test is also performed to check the randomness of fuel cost values obtained in 25 runs.
The investigation of the achieved results reveals that the proposed optimizer successfully finds the optimal active thermal power generation schedule while fulfilling the system constraints. It also provides better convergence characteristics. The proposed optimizer can be implemented for a power system with a number of objectives. Reactive power can be taken into consideration in addition to active power. The dynamic load and multiple fuel options can be considered in further research.

\section{Acknowledgment}

The authors are indebted to the I.K.G. Punjab Technical University, Kapurthala for providing the advanced research facilities for this research work.

\section{Conflicts of interest}

The authors have no conflicts of interest to declare.

\section{References}

[1] Roy PK, Ghoshal SP, Thakur SS. Combined economic and emission dispatch problems using biogeographybased optimization. Electrical Engineering. 2010; 92(4):173-84.

[2] Rao BS, Vaisakh K. Multi-objective adaptive clonal selection algorithm for solving environmental/economic dispatch and OPF problems with load uncertainty. International Journal of Electrical Power \& Energy Systems. 2013; 53:390408.

[3] Lu Z, He S, Feng T, Li X, Guo X, Sun X. Robust economic/emission dispatch considering wind power uncertainties and flexible operation of carbon capture and storage. International Journal of Electrical Power \& Energy Systems. 2014; 63:285-92.

[4] Singh L, Dhillon JS. Best weight pattern evaluation based security constrained power dispatch algorithm. Journal of Systems Science and Systems Engineering. 2007; 16(3):287-307.

[5] Sakthivel VP, Goh HH, Srikrishna S, Sathya PD, Rahim SK. Multi-objective squirrel search algorithm for multi-area economic environmental dispatch with multiple fuels and valve point effects. IEEE Access. 2020; 9:3988-4007.

[6] Kothari DP, Dhillon JS. Power system optimization. 2nd Edition, PHI Learning Private Limited Delhi, 2013.

[7] Güvenc U, Sönmez Y, Duman S, Yörükeren N. Combined economic and emission dispatch solution using gravitational search algorithm. Scientia Iranica. 2012; 19(6):1754-62.

[8] Ghasemi A. A fuzzified multi objective interactive honey bee mating optimization for environmental/economic power dispatch with valve point effect. International Journal of Electrical Power \& Energy Systems. 2013; 49:308-21.

[9] Abdelaziz AY, Ali ES, Abd ESM. Combined economic and emission dispatch solution using flower 
pollination algorithm. International Journal of Electrical Power \& Energy Systems. 2016; 80:264-74.

[10] Rezaie H, Kazemi-rahbar MH, Vahidi B, Rastegar H. Solution of combined economic and emission dispatch problem using a novel chaotic improved harmony search algorithm. Journal of Computational Design and Engineering. 2019; 6(3):447-67.

[11] Dey B, Roy SK, Bhattacharyya B. Solving multiobjective economic emission dispatch of a renewable integrated microgrid using latest bio-inspired algorithms. Engineering Science and Technology, an International Journal. 2019; 22(1):55-66.

[12] Singh L, Dhillon JS. Sensitivity measure for electric power load dispatch problem. Electric Power Components and Systems. 2010; 38(11):1228-47.

[13] Singh L, Dhillon JS. Secure multiobjective real and reactive power allocation of thermal power units. International Journal of Electrical Power \& Energy Systems. 2008; 30(10):594-602.

[14] Kansal V, Dhillon JS. Emended salp swarm algorithm for multiobjective electric power dispatch problem. Applied Soft Computing. 2020.

[15] Hassan MH, Houssein EH, Mahdy MA, Kamel S. An improved manta ray foraging optimizer for costeffective emission dispatch problems. Engineering Applications of Artificial Intelligence. 2021.

[16] Joshi PM, Verma HK. An improved TLBO based economic dispatch of power generation through distributed energy resources considering environmental constraints. Sustainable Energy, Grids and Networks. 2019.

[17] Chatterjee A, Ghoshal SP, Mukherjee V. Solution of combined economic and emission dispatch problems of power systems by an opposition-based harmony search algorithm. International Journal of Electrical Power \& Energy Systems. 2012; 39(1):9-20.

[18] Sayah S, Hamouda A, Bekrar A. Efficient hybrid optimization approach for emission constrained economic dispatch with nonsmooth cost curves. International Journal of Electrical Power \& Energy Systems. 2014; 56:127-39.

[19] Chopra N, Brar YS, Dhillon JS. An improved particle swarm optimization using simplex-based deterministic approach for economic-emission power dispatch problem. Electrical Engineering. 2021; 103(3):134765.

[20] Sharifzadeh H. Sharp formulations of nonconvex piecewise linear functions to solve the economic dispatch problem with valve-point effects. International Journal of Electrical Power \& Energy Systems. 2021

[21] Chang X, Xu Y, Sun H, Khan I. A distributed robust optimization approach for the economic dispatch of flexible resources. International Journal of Electrical Power \& Energy Systems. 2021.

[22] Hota PK, Barisal AK, Chakrabarti R. Economic emission load dispatch through fuzzy based bacterial foraging algorithm. International Journal of Electrical Power \& Energy Systems. 2010; 32(7):794-803.
[23] Kumar M, Dhillon JS. A conglomerated ion-motion and crisscross search optimizer for electric power load dispatch. Applied Soft Computing. 2019.

[24] Nasir M, Sadollah A, Aydilek İB, Ara AL, Nabaviniaki SA. A combination of FA and SRPSO algorithm for combined heat and power economic dispatch. Applied Soft Computing. 2021.

[25] Goudarzi A, Li Y, Xiang J. A hybrid non-linear timevarying double-weighted particle swarm optimization for solving non-convex combined environmental economic dispatch problem. Applied Soft Computing. 2020.

[26] Srivastava A, Das DK. A new Kho-Kho optimization Algorithm: An application to solve combined emission economic dispatch and combined heat and power economic dispatch problem. Engineering Applications of Artificial Intelligence. 2020.

[27] Xin-gang Z, Ji L, Jin M, Ying Z. An improved quantum particle swarm optimization algorithm for environmental economic dispatch. Expert Systems with Applications. 2020.

[28] Kaur S, Brar YS, Dhillon JS. Real-time short-term hydro-thermal-wind-solar power scheduling using meta-heuristic optimization technique. International Journal of Renewable Energy Development. 2021; 10(3):635-51.

[29] Chopra N, Brar Y, Dhillon J. Economic power dispatch using hybrid particle swarm optimization with simplex search method. ECTI Transactions on Electrical Engineering, Electronics, and Communications. 2020; 18(1):70-9.

[30] Narimani H, Razavi SE, Azizivahed A, Naderi E, Fathi M, Ataei MH, et al. A multi-objective framework for multi-area economic emission dispatch. Energy. 2018; 154:126-42.

[31] Liang H, Liu Y, Li F, Shen Y. A multiobjective hybrid bat algorithm for combined economic/emission dispatch. International Journal of Electrical Power \& Energy Systems. 2018; 101:103-15.

[32] Rex CE, Beno MM, Annrose J. A solution for combined economic and emission dispatch problem using hybrid optimization techniques. Journal of Electrical Engineering \& Technology. 2019.

[33] Xu Z, Zhang K. Multiobjective multifactorial immune algorithm for multiobjective multitask optimization problems. Applied Soft Computing. 2021.

[34] Hu Z, Li Z, Dai C, Xu X, Xiong Z, Su Q. Multiobjective grey prediction evolution algorithm for environmental/economic dispatch problem. IEEE Access. 2020; 8:84162-76.

[35] Dong R, Wang S. New optimization algorithm inspired by kernel tricks for the economic emission dispatch problem with valve point. IEEE Access. 2020; 8:16584-94.

[36] Hassan MH, Kamel S, Salih SQ, Khurshaid T, Ebeed M. Developing chaotic artificial ecosystem-based optimization algorithm for combined economic emission dispatch. IEEE Access. 2021; 9:51146-65.

[37] Deb S, Abdelminaam DS, Said M, Houssein EH. Recent methodology-based gradient-based optimizer 
for economic load dispatch problem. IEEE Access. 2021; 9:44322-38.

[38] Wang J, He X, Huang J, Chen G. Recurrent neural network for nonconvex economic emission dispatch. Journal of Modern Power Systems and Clean Energy. 2020; 9(1):46-55.

[39] Fayyaz S, Sattar MK, Waseem M, Ashraf MU, Ahmad A, Hussain HA, et al. Solution of combined economic emission dispatch problem using improved and chaotic population-based polar bear optimization algorithm. IEEE Access. 2021; 9:56152-67.

[40] Wolpert DH, Macready WG. No free lunch theorems for optimization. IEEE Transactions on Evolutionary Computation. 1997; 1(1):67-82.

[41] Mandal B, Roy PK, Mandal S. Economic load dispatch using krill herd algorithm. International Journal of Electrical Power \& Energy Systems. 2014; 57:1-10.

[42] Cui X, Chen Z, Yin F. Differential evolution and local search based monarch butterfly optimization algorithm with applications. International Journal of Computational Intelligence Systems. 2018; 12(1):14963.

[43] Roy PK, Bhui S. Multi-objective quasi-oppositional teaching learning based optimization for economic emission load dispatch problem. International Journal of Electrical Power \& Energy Systems. 2013; 53:93748 .

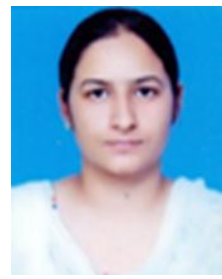

Amarjeet Kaur obtained her B. Tech (Electrical) (2002) from Guru Nanak Dev Engineering College, Ludhiana, M.Tech. (Power Engineering) (2008) from Guru Nanak Dev Engineering College, Ludhiana. She is the author of 6 technical papers published in national and international journals /conferences. Her research interests include Power System Analysis and Power System Operation and Control.

Email: amarjeet.kaur@bbsbec.ac.in

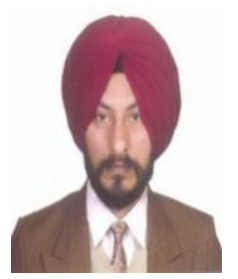

Dr. Lakhwinder Singh obtained his B.E. (Electrical) (1990) from Guru Nanak Dev Engineering College, Ludhiana, M.E. (Power Systems) (1995) from Punjab University, Chandigarh and Ph.D (2009) from Punjab Technical University, Jalandhar. $\mathrm{He}$ is a life member of the Indian Society for Technical Education and a fellow of the Institution of Engineers (India). He is the author of 67 technical papers published in national and international journals/conferences. His research interests include Neural Networks, Fuzzy Logic, Optimization Techniques, Power System Operation and Control.

Email: b_lakh@yahoo.com

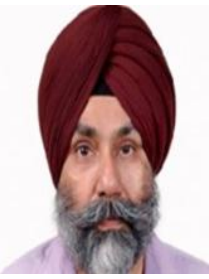

Dr. Jaspreet Singh Dhillon received his B.E. (Electrical) (1983) from Guru Nanak Dev Engineering College, Ludhiana, M.E. (Systems) (1987), Punjab Agricultural University, Ludhiana, Ph.D., (1996) from Thapar Institute of Engineering \& Technology, Patiala. He has published/ presented more than 190 papers in national and international journals/ conferences. He supervised 20 Ph.D. and 33 M.E. scholars. His research activities include Microprocessor applications, Multi-objective thermal dispatch, hydrothermal scheduling, Optimization, Neural networks, Fuzzy Theory and Soft Computing Applications in Power system and co-authored 03 books "Power System Optimization", Prentice-Hall of India, New Delhi, "Digital Circuits and Design", Pearson Education, New Delhi and "Basic Electrical \& Electronics Engineering", Kalyani Publishers and Contributed to Power System Engineering, 3rd Edition, McGraw Hill Education (India) Private Ltd, New Delhi.

Email: jsdhillon62@gmail.com

Appendix I

\begin{tabular}{|c|c|c|}
\hline S. No. & Abbreviation & Description \\
\hline 1 & $B_{00}, B_{i 0}$ and $B_{i j}$ & $\begin{array}{ll}\text { Transmission } & \text { Loss } \\
\text { Coefficients } & \\
\end{array}$ \\
\hline 2 & $C_{R}$ & Crossover Probability \\
\hline 3 & $C_{t}$ & Position Constant Factor \\
\hline 4 & $D_{k}$ & Random Diffusion \\
\hline 5 & $D_{\max }$ & $\begin{array}{lll}\text { Maximum } \\
\text { Diffusion }\end{array}$ \\
\hline 6 & EEPD & $\begin{array}{l}\text { Economic-Environmental } \\
\text { Power Dispatch }\end{array}$ \\
\hline 7 & ELD & Economic Load Dispatch \\
\hline 8 & $F_{k}^{w}$ and $F_{k}^{b}$ & $\begin{array}{l}\text { Worst and Best Position of } \\
\mathrm{k}^{\text {th }} \text { Krill }\end{array}$ \\
\hline 9 & $F_{k}$ and $F_{j}$ & $\begin{array}{l}\text { Fitness Values of } \mathrm{K}^{\text {th }} \text { and } \\
\mathrm{J}^{\text {th }} \text { Krill }\end{array}$ \\
\hline 10 & $F_{k}^{\text {best }}$ & $\begin{array}{l}\text { Best Value of Fitness } \\
\text { Function }\end{array}$ \\
\hline 11 & $F G_{k}^{m}$ and $F G_{k}^{m-1}$ & $\begin{array}{l}\text { Foraging Motions of the } \\
\mathrm{k}^{\text {th }} \text { krill at } \mathrm{m}^{\text {th }} \text { and }(\mathrm{m}-1)^{\text {th }} \\
\text { Movements }\end{array}$ \\
\hline 12 & $\mathrm{~h}$ & Price Penalty Function \\
\hline 13 & HKHO & $\begin{array}{lll}\text { Hybrid } & \text { Krill } & \text { Herd } \\
\text { Optimizer } & & \\
\end{array}$ \\
\hline 14 & $I T_{\max }$ & Maximum Iterations \\
\hline 15 & KHA & Krill Herd Algorithm \\
\hline 16 & $M_{R}$ & Mutation Rate \\
\hline 17 & MODE & $\begin{array}{l}\text { Multi-objective } \\
\text { Differential Evolution }\end{array}$ \\
\hline 18 & $m$ & Current Iteration \\
\hline 19 & NFE & $\begin{array}{l}\text { Number of Function } \\
\text { Evaluation }\end{array}$ \\
\hline 20 & NK & Number of Krill \\
\hline 21 & NG & $\begin{array}{l}\text { Number of Thermal Power } \\
\text { Generating Units }\end{array}$ \\
\hline 22 & NSGA & $\begin{array}{l}\text { Non-dominated Sorting } \\
\text { Genetic Algorithm-II }\end{array}$ \\
\hline 23 & $N_{k}^{\max }$ & Maximum Induced Motion \\
\hline 24 & $N_{k}^{m}$ & $\begin{array}{l}\text { Induced Motion at } \mathrm{m}^{\text {th }} \\
\text { Movement }\end{array}$ \\
\hline 25 & $N_{k}^{m-1}$ & Induced Motion at $(\mathrm{m}-1)^{\mathrm{th}}$ \\
\hline
\end{tabular}


Amarjeet Kaur et al.

\begin{tabular}{|c|c|c|}
\hline & & Movement \\
\hline 26 & Ns & $\begin{array}{l}\text { Number of Neighboring } \\
\text { Krill }\end{array}$ \\
\hline 27 & PDE & $\begin{array}{ll}\text { Pareto } & \text { Differential } \\
\text { Evolution } & \end{array}$ \\
\hline 28 & PSO & $\begin{array}{ll}\text { Particle } & \text { Swarm } \\
\text { Optimization } & \end{array}$ \\
\hline 29 & POZ & $\begin{array}{ll}\text { Prohibited } & \text { Operating } \\
\text { Zones } & \\
\end{array}$ \\
\hline 30 & $P_{k}^{m}$ & Old Krill Position \\
\hline 31 & $P_{k}^{m+1}$ & $\begin{array}{l}\text { Updated Position of } \mathrm{k}^{\text {th }} \\
\text { Krill }\end{array}$ \\
\hline 32 & $P_{i}^{\text {selected }}$ & Selected Krill Position \\
\hline 33 & $P_{D}$ & Power Demand \\
\hline 34 & $\Delta P_{D}$ & Change in Power Demand \\
\hline 35 & $P_{i}^{\min }$ & $\begin{array}{l}\text { Lower Limit of Active } \\
\text { Power Generation of } i^{t h} \\
\text { Unit }\end{array}$ \\
\hline 36 & $P_{i}^{\max }$ & $\begin{array}{l}\text { Upper Limit of Active } \\
\text { Power Generation of } i^{\text {th }} \\
\text { Unit }\end{array}$ \\
\hline 37 & $P_{i}$ & $\begin{array}{l}\text { Active Power Generation } \\
\text { of } i^{t h} \text { Unit }\end{array}$ \\
\hline 38 & $P_{k i}$ & Real Power Vector \\
\hline 39 & $P_{k}^{\text {best }}$ & Position of $\mathrm{k}^{\text {th }}$ Krill \\
\hline 40 & $P_{k i}^{\bmod }$ & $\begin{array}{l}\text { Modified Value of Krill's } \\
\text { Position }\end{array}$ \\
\hline 41 & QOTLBO & $\begin{array}{l}\text { Quasi-opposition Teaching } \\
\text { Learning } \\
\text { optimization }\end{array}$ \\
\hline 42 & SPEA-2 & $\begin{array}{l}\text { Strength Pareto } \\
\text { Evolutionary Algorithm } 2\end{array}$ \\
\hline 43 & TLBO & $\begin{array}{l}\text { Teaching Learning Based } \\
\text { Optimization }\end{array}$ \\
\hline 44 & $V_{f}$ & $\begin{array}{ll}\text { Foraging Rate } & \text { To } \\
\text { Discover Food } & \end{array}$ \\
\hline 45 & $\omega_{f}$ & Foraging inertia weight \\
\hline 46 & $\omega_{n}$ & Induced Inertia Weight \\
\hline 47 & $\alpha_{1 \mathrm{i}}, \beta_{1 \mathrm{i}}, \gamma_{1 \mathrm{i}}, \delta_{1 \mathrm{i}}$ and $\lambda_{1 \mathrm{i}}$ & Fuel Cost Coefficients \\
\hline 48 & $\alpha_{2 \mathrm{i}}, \beta_{2 \mathrm{i}}, \gamma_{2 \mathrm{i}}, \delta_{2 \mathrm{i}}$, and $\lambda_{2 \mathrm{i}}$ & Emission Coefficients \\
\hline
\end{tabular}

